\title{
Relatives' experiences of everyday life when receiving day care services for persons with dementia living at home
}

\author{
- "It's good for her and its good for us"
}

\author{
Gunn Eva Solum Myren ${ }^{1,2,3^{*}}$, Ingela Enmarker ${ }^{1,2}$, Ellen Saur ${ }^{4}$, Ove Hellzen $^{1,2,3}$ \\ ${ }^{1}$ Centre for Care Research, Mid-Norway, Steinkjer, Norway; ${ }^{*}$ Corresponding Author: gunn-eva.s.myren@hint.no \\ ${ }^{2}$ Faculty of Health Sciences, Nord-Trøndelag University College, Namsos, Norway \\ ${ }^{3}$ Department of Health Science, Mid-Sweden University, Sundsvall, Sweden \\ ${ }^{4}$ Department of Education, Norwegian University of Science and Technology, Trondheim, Norway
}

Received 27 May 2013; revised 27 June 2013; accepted 15 July 2013

Copyright (c) 2013 Gunn Eva Solum Myren et al. This is an open access article distributed under the Creative Commons Attribution License, which permits unrestricted use, distribution, and reproduction in any medium, provided the original work is properly cited.

\begin{abstract}
Relatives often become involved in the care of people with dementia who are living at home. The caregivers' burdens are extensively described in several studies, and one of the most common, unmet needs of the caregivers is the opportunity for daytime activities. The aim in this qualitative study is therefore to explore the everyday lives of eight relatives of people with dementia who are receiving day care services. A content analysis is used, and three major themes emerge and are discussed: 1) when life becomes chaotic; 2 ) rebuilding a new, everyday life; and 3) the agonies of choice. The findings indicate that day care service offers respite care, and, at the same time, it gives both the relatives and those with dementia a meaningful day. These findings can also be described as relatives traveling a route from a situation characterized by chaos and suffering to a new life situation that has meaning through day care services. It is important to note that despite this new meaning in the relatives' lives, the relatives continue to struggle with decisions about the futures of their loves ones in regard to the dilemma of placing them in an institution versus aging in place.
\end{abstract}

Keywords: Relatives; Caregiver; Dementia; Day Care; Qualitative Content Analysis

\section{INTRODUCTION}

The term "dementia" is an umbrella term that is used to describe a large class of disorders characterized by progressive decline in cognitive functions. This decline typically includes loss of memory and judgment as well as changes in mood and behavior, communication and functional ability in everyday life. There is no cure for dementia, which remains the leading cause of dependency and disability amongst older people [1].

The worldwide prevalence of people living with dementia was estimated by WHO to be 35.6 million in 2010, and is expected to double by 2030 and more than triple by 2050 [2]. There are approximately 70,000 persons with dementia in Norway today. About 35,000 of them are living at home, and this number will increase to approximately 40,000 in 2020 [3]. The Norwegian government has set the focus on the growing number of people with dementia the last decade. In the national plan for dementia, one focus area is day care services for people with dementia, and the aim of this care is to help them to stay at home for as long as possible [4]. This is also in line with the wishes of the majority of people with dementia [5]. Dementia not only affects the person who has the condition but also his or her relatives and family members [2]. Most people with dementia have at least one caregiver, usually a spouse or relative. Chumbler et al. (2003) found no difference in caregiver burden between adult children and spouses [6]. In general, closer kinship ties are associated with increased caregiving duties [7]. Caregivers' experiences of the stresses and burdens of care are well known. Depression, anxiety, fatigue, sleep disturbances and lack of time for pleasurable activities have been well documented as effects of the caregiving burden [8-10]. The stressors can briefly be described as physical, emotional and economic burdens 
[11]. Van den Wijngaart et al. (2007: p. 634) claim that "a caregiver becomes burdened when there is a misbalance between the care load (stressors) and the capacity to function in daily life (functional health status)" [12]. One of the most common unmet needs of the caregivers is time for daytime activities [13]. There are different kinds of daytime activities. Respite care in the form of day care services is one of several respite services that aim to provide temporary relief to caregivers from their responsibilities of caring for a loved one with dementia. Regular day care facilities have traditionally been care-oriented, while nursing home environments have a more or less medical orientation [14]. In the last decade, there is a trend toward increased attention to day care facilities as an important area of community services [15]. The facilities that lie beyond institutions are more socially oriented [14], such as Green care farms (GCFs). These farms combine agricultural production with care services for people with care needs, e.g., persons with dementia. GCFs provide day care services in a non-institutional and outdoor environment, which gives the person with dementia opportunities to participate in a purposeful activity in addition to leisure and recreational activities domestic activities, and farm-related and outdoor activities. These activities stimulate the older people with dementia to be physically active and to interact with nature, animals and other people [16]. The aim of this study is to explore the everyday lives of relatives of people with dementia who are receiving day care services.

\section{METHOD}

A qualitative approach with semi-structured interviews and open-ended questions was used for this study. According to Kvale (2007: p.11), semi-structured interviews “... seek to obtain descriptions of the life-world of the interviewee with respect to interpreting the meaning of the described phenomenon" and allow follow-up questions [17]. The relatives were asked about how they experienced everyday life before and after receiving day care services for their loved ones with dementia, and they were also asked to talk about the future in relation to their loved ones. The interviews were conducted between February and May 2012. The length of the interviews was between 45 and 90 minutes, and they were conducted in-person and face-to-face. The first author tape recorded and transcribed the interviews as well as described the context where the interviews were conducted. Those observation notes were later used in the analysis to help the researches to understand the interview setting and the context.

\subsection{Participants and Context}

During qualitative research, variation should be considered when choosing participants for a study [17]. The number of informants depends on the need to obtain as great a variation of data as possible [18]. In this study, eight relatives were interviewed.

Table 1 shows an overview of what characterizes the informants. The informants were recruited by the project leaders in four different day care projects. The day care projects were GCFs in four municipalities in the middle of Norway. The two inclusion criteria were that the loved ones lived in their own homes and that the relatives were receiving day care services from one of these four GCFs projects.

The GCFs varied both in size and in number of day care services delivered per week. The size varied from five to eight participants with dementia, and the number of daycare visits per week ranged from one day every other week to two days per week. All of the activities on the GCFs were related to farming, the domestic setting home-like, or outdoor environments. The four different day care projects" (GCFs) in this study have equally good hardware (e.g. environment) and software (e.g. day care services workers) and provide similar functions of small group social life to the persons with dementia. In addition, three of the persons with dementia received day care services in regular day care facilities once a week. We are not comparing the day care services in this study, but see them both (i.e., the regular day care services and GCFs) as day care services with the purpose of reducing caregiver burden.

Table 1. Informants characteristics.

\begin{tabular}{ccccc}
\hline $\begin{array}{c}\text { Gender } \\
\text { (relatives) }\end{array}$ & $\begin{array}{c}\text { Age } \\
\text { (relatives) }\end{array}$ & Relationship & $\begin{array}{c}\text { Gender } \\
\text { person with dementia) }\end{array}$ & $\begin{array}{c}\text { Distance between } \\
\text { each other }\end{array}$ \\
\hline Female & 61 & Daughter & Male & $6,0 \mathrm{~km}$ \\
services per month & 8 \\
Female & 60 & Daughter & Female & $300 \mathrm{~m}$ \\
Male & 82 & Husband & Fale & 0 \\
Female & 34 & Grandchild & Female & $4,0 \mathrm{~km}$ \\
Female & 57 & Son & Female & $14,0 \mathrm{~km}$ \\
Male & 58 & Niece & Female & $400 \mathrm{~m}$ \\
Female & 55 & Daughter & Male & $600 \mathrm{~km}$ \\
Female & 42 & 8 & $2,0 \mathrm{~km}$ \\
\hline
\end{tabular}




\subsection{Analysis}

A content analysis was performed to analyze the transcribed material [18-20]. The interviews were read through several times to get a sense of the whole. The first author organized the data in a timeline to reduce the data by eliminating text that was not relevant to the aim and purpose of the study. The other reason for creating the timeline was that the relatives talked about the time before and after receiving respite care [21]. Further on, the data were organized into meaning units with codes before they were extracted to a more latent level with sub-themes and themes. During the analysis, the data and the process of labeling and creating categories and themes were discussed with the second and third au thors. Three main themes emerged from the analysis. Table 2 provides examples of this analysis.

\subsection{Ethics}

Ethical approval from the Norwegian Regional Ethical Committee North was obtained before the start of the study. Written, informed consent was obtained initially; however, at each interview, the information was repeated, and consent was obtained orally. During all of the interviews, the interviewer sought to establish a safe and gentle atmosphere by speaking to the respondents in a friendly and reassuring manner [22]. According to the informants' wishes, six interviews were conducted at the homes of the primary caregivers, and two interviews took place at other locations. The project leaders from the four day care projects also served as emotional backup for the relatives if they needed somebody to talk to after the interviews.

\section{RESULTS}

Three main themes were identified and named, "When life becomes chaotic," "Rebuilding a new, everyday life," and "The agonies of choice." The results of the analysis show that the first two of these three main themes have two sub-themes. The first sub-theme represented the direct experiences of the relatives themselves, and the second sub-theme represented indirect experiences through their loved ones. The third and last main theme includes one sub-theme.

\subsection{When Life Becomes Chaotic}

The first theme is about the time before the day care services began. The relatives described their everyday lives during this period as very stressful and unpredictable, and it was a time marked by a feeling of chaos, both for the person with dementia and the relatives. One of the relatives said, "It is complete chaos. And I'm beginning to think of how this is going to turn out."

\subsection{The Duty and the Burden}

Every relative described how he or she experienced his or her own feelings, such as "I'm so exhausted" or "I have such a bad conscience about her." This first subtheme explores the relatives' feelings of grief, their guilty consciences, their reversal of roles, the conflict between siblings, and the organizational and practical work that they had to handle in their everyday lives.

All of the relatives talked about the feeling of loss; they explained that they were losing their loved ones, and described the situation as having to get to know them again from scratch. One daughter described it this way: "It's a grief over losing her ... over the person she used to be."

The experience of reversing roles was also very common amongst the relatives. From childhood, their parents or loved ones had been taking care of them; now the situation was completely turned around. One son said, "Seriously, am I really going to talk to my mother about her personal hygiene?” Or, as a daughter said, “... and that was such a fight then to get him to change clothes ... because I was very particular then when I got there too so I'm like, knew that it smelled a little too and could see that he had spilled on himself so he had to change. And it was ... almost like getting a child to do that because he refused." The relatives also talked about how difficult it was to be put in a position where they had to make several different decisions on behalf of the person with dementia.

Having a guilty conscience made the everyday lives of the relatives very exhausting and difficult to handle. There was no difference between relatives who were living nearby or in the same house and relatives living a long distance from their loved ones. One of the relatives,

Table 2. From meaning unit to theme 2.

\begin{tabular}{|c|c|c|c|c|}
\hline Meaning unit & Condenced meaning unit & $\begin{array}{l}\text { Interpretation of the } \\
\text { underlying meaning }\end{array}$ & Sub-theme & Theme 2 \\
\hline $\begin{array}{l}\text { I was very pleased when she got the daycare } \\
\text { because then I could rest a while. It's just like } \\
\text { that. And I know that they took care of her. }\end{array}$ & $\begin{array}{l}\text { Somebody else are taking } \\
\text { care of the loved ones }\end{array}$ & Less stress and burden & Feeling secure & $\begin{array}{l}\text { Rebuilding } \\
\text { an new }\end{array}$ \\
\hline $\begin{array}{l}\text { I don't think she have had such a social } \\
\text { and rich life after the retirement as now. }\end{array}$ & $\begin{array}{l}\text { Social and rich life } \\
\text { after retirement }\end{array}$ & $\begin{array}{l}\text { Everybody have } \\
\text { a social need }\end{array}$ & $\begin{array}{l}\text { Having a meaningful } \\
\text { everyday life }\end{array}$ & everyday life \\
\hline
\end{tabular}


a niece, said, “I haven’t been there since January ... and now ... it's too long ... but it is so busy and ... I have constantly a bad conscience about her because I'm thinking that she is sitting alone.” The feeling of not doing enough or visiting enough was a common experience for the relatives.

Some of the relatives, especially sons and daughters, talked about the conflict between siblings. The conflict was usually about who should do what and when. Often, the siblings living closest to their mom or dad felt this extra burden. One daughter said, living $300 \mathrm{~m}$ from her mother; "I have one sister, but she doesn't live around here. She lives in another municipality. So I felt when she came visiting our mom that she was visiting her, but I couldn't do that. I had to do some work for mom. Do you understand?" The adaptations or organizing for the persons with dementia in their own homes were other burdens or duties that the relatives experienced. They had to help their loved ones with practical chores like the installation of a stove guard to prevent dangers such as a kettle boiling dry, filling out different forms, taking over financial concerns, and doing laundry or other household chores, such as cleaning the floors or shopping. These activities demand time and attention from the relatives and their own families, and a lot of them did these chores after they came from work. The time spent on these activities led to the feeling of "missing quality time" with their loved ones. It was more often described as a duty than as a desire to help. The distance living from their loved ones, does not seems to matter or affect the experience of having a responsibility for the person with dementia.

\subsection{Time Out from a Social Life}

The second sub-theme refers to what the relatives described as a passivity and social withdrawal that they could see in the person with dementia. This withdrawal also contributes to the relatives' bad feelings, because their loved ones do not seem to have the kind of social life that they used to have. One daughter put it this way: "We felt that she became very passive and she was very anxious ... she had always been such a social person, but now it's like nothing ... she says she is neither able to or willing to do anything." Other relatives describe the person with dementia as sleeping a lot, staying inside the house, not visiting old friends, and not participating in their usual activities, such as café visits, going for a walk, or participating in other leisure-time activities with their friends.

\subsection{Rebuilding a New, Everyday Life}

Theme two describes relatives' experiences after receiving day care. The relatives described how things were falling into place after a period of chaos. They mentioned that they are starting to establish a new platform with new routines for the everyday lives of themselves and their loved ones. The relatives' experiences are represented by two sub-themes. On the one hand, they talked about the feeling of security, and, on the other hand, they talked about the person with dementia needing to have a meaningful day.

\subsection{Feeling Secure}

The relatives said that they do feel safe and secure when they know that their loved ones are being cared for. One daughter said, "Knowing that somebody is taking care of her. That is a security.” The niece living far away from her aunt expressed it like this: "It is perhaps, that she will be taken care of (...) Thus I do not know how it would have gone without? I do not because, I would have been sitting here and she is there and no it (...) But we know that it fills her time and I think it does very well for her and it does very well for us.” This security also leads to the relatives' being able to pursue their interests, and they could cope with the needs of everyday life more easily. A husband said, "It should expand day care. I should like to have one day every week ... then I could take my time when I have to go to the city for some errands. Yes, and yesterday I even went outside for a walk ...” Other relatives pointed out clearly that day care gives them an opportunity to rest when their loved ones are receiving the assistance. As one daughter said, "But she could not do anything in the end. So it was a year that was a little awkward. Therefore, I was very happy when she got day care for two days, then I could rest and do different stuff for myself (...) and I knew that she was being looked after.”

\subsection{Having a Meaningful Everyday Life}

Knowing that day care was offering the persons with dementia meaningful activities and thereby meaningful days was important to the relatives. Under this sub-theme, the relatives showed the importance of their own wellbeing in knowing that their loved ones were having a meaningful day. The relatives were speaking of social life in terms of the person with dementia having somebody to talk to, having fellowship, and thus flourishing. One daughter expressed it like this: "It sounds like she does not want to live if she cannot go there (at the day care services). It is top of everything. And about the day care, they told me really, really fast the staff that worked there that mom just got better and better. She flourished during the days she was there. I felt it also ...” A grandchild said about her grandmother, "I don't think she has had such a social and rich life after retirement as [she has] now." The relatives also appreciated the physical activi- 
ties at the day care. They talked about how their loved ones were walking on a forest path or in the forest, picking berries, or feeding the horses and the sheep in the fields. They also mentioned the importance of other types of activities related to handicraft, music, or housework, such as preparing dinner or doing the dishes. Activities that give their loved ones a meaningful day and thereby help to maintain their skills are of great value to the relatives.

\subsection{The Agonies of Choice: What about the Future?}

In this last theme, the relatives expressed their uncertainty about how to handle or to think about the future. The relatives struggle with the decision of whether to move their loved one to a nursing home. They felt a commitment toward keeping the person with dementia in his or her home for as long as possible, and the relatives also offered some reflections about the dignity and selfdetermination of persons with dementia. One relative said, "She is not declared to be without legal capacity and she does decide about her own life. Of course she does that, but at the same time, she does not know what she is deciding about ...”

\subsection{Going to an Institution vs. Aging in Place}

On one hand, the relatives wish for a place for their loved ones so they can better cope with everyday life and, in one way, to get some relief from the burden of daily caregiving. On the other hand, they also think about their loved ones' dignity and self-determination. One daughter said, "I do wish for a place at the special care unit for her, because then I feel I could have avoided the bad conscious. It's a sort of egoism in it. ... It is very, very difficult. Because ... I also want her to feel that she can contribute with her skills and resources. I do believe that that is important ... and that is what makes me so uncertain. ... She can take good care of herself, you know, and if she ... if we take away things that she can handle very well ... it's about human decency...”

There are also relatives who are very clear that they do not want the person with dementia to go to an institution, because they “don't belong there,” or because the loved ones are bonded to their homes; as another daughter said, "I do hope we can have this arrangement as long as possible, so dad can stay at home as long as possible, because I can see that he can manage to take care of himself very good. ... Daddy wants to stay at home. He said ... he is also very attached to his home."

\section{DISCUSSION}

In this study, the aim was to explore the everyday lives of relatives of people with dementia receiving day care services. When a person is diagnosed with cognitive impairment, the relatives are affected one way or another. In this study, the relatives give us insights into how their lives change as they care for their loved ones before and after the person with dementia began to receive day care services as well as insights into their struggles to make decisions about the futures of their loved ones.

To be a relative of a person with dementia is a challenging situation that puts him or her in a vulnerable position. Golden (2012) identified different metaphors that were used to describe the caregivers' burden and what it was like to be a caregiver. "Pathway" was one of those metaphors. When the person with dementia receives the diagnosis, there is no turning back, so a new life as a caregiver can perhaps be described as being in a jungle where the "pathways" are broken [23]. In this particular study, the relatives characterized their new life situations as chaotic, that is, a situation of confusion and uncertainness.

Grief over their loved one's illness, guilty consciences, and the complex situation of changing roles affect the relatives in different ways [24]. Several relatives talked about how they had to handle the practical aspects of everyday life, such as grocery shopping and cleaning. Making time to help the person with dementia was experienced as a duty, which led to emotions such as grief, a bad conscience, and the experience of loss. According to Adams (2008), each stage of dementia has its particular emotional tasks, and the feeling of loss will influence the quality of the relationship with the loved one [25]. Therefore, the feeling of loss will be a constant emotion during the illness that the relatives must handle adaptively. Relatives' experiences of burden and stress are described in several studies [7,9,12], and the results of this study are in line with those findings.

Family conflicts or conflicts among siblings also led to greater strain and stress when it came to coping with caring for the person with dementia [26]. For the sibling who lives closest to the loved one, the burden of carrying the responsibility can be a difficult struggle [27].

Social isolation and loneliness is also a topic to which the relatives refer as another challenge. The relatives experienced that the persons with dementia withdrew from social life, and thus became lonely. In our study, the result can suggest that persons with dementia increased their social life when they began to receive day care services. This increase may be because of different factors, such as the feeling of fellowship. Moreover, they still regained the feeling of having a meaningful day through day care services [28]. Nevertheless, one study from Australia shows that placing persons with dementia into new environments or with unfamiliar people does not necessarily decrease feelings of loneliness [29]. 
In this study, the relatives were of the opinion that day care services are both respite care and a place where the persons with dementia could have a meaningful day. Gústavsdóttir (2011) also concludes that a well-organized day care service not only provides respite care for the relatives but also supports and enriches the loved one's life [30]. Surprisingly few relatives were talking of or expressed a clear relief of having a break from their loved ones, which may be because only the husband was living in the same household as the person with dementia, i.e., his wife. Nevertheless, having respite from caregiving gave some of the relatives opportunities to do things that they had been doing before the diagnosis, and they felt it was like a real break [31], or they used their "break" to do different things [32]. Instead of expressing clearly the need for a break in everyday life, the relatives expressed their feelings of assuredness that their loved ones were receiving good care in a safe and secure environment. It seems that knowing their loved ones were having a meaningful day and were receiving good care may lead to a form of safety and a reduction of caregiver burden amongst the relatives. The relatives could cope better in their everyday lives and explore more of the meaning of the life situation $[8,33]$.

In addition, the fact that several of the relatives experienced that day care services was allowing the persons with dementia to take walks outside in the forest or to do other physical activities outdoors was of great importance to the relatives. Spending time outdoors doing different activities like walking, picking berries or flowers, and so on increased the quality of life and offered health benefits [16]. Several of the relatives were talking about how their loved ones flourished after they started the day care services. They claimed that this flourish came from participation in activity or in the social community that allowed their loved ones to rely upon their individual coping capabilities and to pursue personal interest. It may therefore seem that day care service can offer customized and personalized activities that engage persons with dementia in small groups. In spite of all these positive thoughts about the day care services, the relatives still face challenges.

The relatives are in a position where they have to make some choices for the person with dementia; they are struggling to discern what the right choice is. Making a decision about placing a loved one with dementia into a nursing home is one of the most painful and difficult processes of the relatives' caregiving trajectory [34]. Making this choice leads to guilt and distress, which is also described in other studies [35,36]. Some studies placed special emphasis on the relatives' decision-making process concerning "going to an institution or aging in place." For example, Butcher et al. (2001) described the relatives' experiences with the transfer to an institu- tion in four steps: moving toward the unavoidable decision, struggling with the decision, seeking reassurance, and remaining connected [37]. The relatives expressed different reasons for starting to think about the future and the decision about a nursing home. For some of the relatives in this study, the decision is about the progress of the dementia and the increasing scope of the caregiving burdens over time; for the other caregivers, the decision is related to a more acute situation, such as a fall, or it could be in response a proposal from the home care nurses [34]. Although the relatives were concerned with when and how they should ask for help to make such decisions, they also had their own thoughts about the loved one's self-determination and dignity. In other words, the relatives were facing a dilemma: their loved one's wishes and capabilities to make the right decision did not align with their responsibility to make a choice on behalf of the person with dementia. One study from the United States found that the decision-making moved from the use of autonomy to the use of beneficence as the core principle in guiding decisions [38]. In that way, it becomes easier to make the right choice for the loved one. The broken pathways described by Golden (2012) [23] may lead to a point where the relative experiences suffering because of the new situation and the feelings of chaos. According to Eriksson (2006), suffering is a part of human life [39].

\subsection{From Suffering to Meaning}

When faced with the incurable illness of a loved one, relatives also face potential suffering and will, at some point, ask themselves the meaning of suffering. This perspective is valid in all forms of caregiving, and it is important for relatives coping with the burdens of caregiving. If we look at suffering as a concept, we can imagine it as a prism where different perspectives and dimensions take part. There is a positive and a negative dimension, where desire for happiness and enjoyment is the opposite of suffering, according to Eriksson [39]. The suffering can imply that energy is lost and that the person is filled with depression. The relatives have an implicit and moral responsibility to care for the ill person, and many also want to do this [40]. As caregivers for the person with dementia, relatives can also be considered victims of the illness, because the illness also puts them in positions of suffering. Demanding caregiving responsibilities and the doubt about making the right decisions will always be a part of the relatives' lives and thus cause them to suffer. In a situation characterized by suffering, it is important to find meaning in the suffering [39]. Frankl (1969) describes three ways of finding meaning in life: by doing works or deeds; by experiencing beauty, goodness, truth, and nature or encountering another person in 
his/her uniqueness by loving him/her; and by choosing an attitude toward unavoidable suffering and being challenged to change oneself. According to Quinn (2010), the relatives' ability to find meaning in caregiving, to derive something positive out of it, could reinforce their desire to provide care [28]. By accepting the changes in the lives of their loved ones, the new caregiving situation, and the new life situation for themselves, relatives may rather cherish the joy they still have instead of focusing on grief and loss [41]. In this study, the relatives point toward finding meaning through day care services, where several opportunities open up for happiness and enjoyment for both the person with dementia and his or her relatives. Frankl (1969) claimed that we discover meanings; we do not invent them [42]. Reconciliation with the new life situation may therefore contribute to the discovery of meaning. On the other hand, Frankl (1969) says that we have a choice and can find meaning by changing our attitudes. If we look at day care as an intervention that helps relatives to change their attitudes and to make discoveries, then we may see that it gives the relatives an opportunity to rebuild an everyday life with the person with dementia based on the meaning that they build. At the same time, the agony of making choices will always be a part of the relatives' lives as an ethical demand [43].

\subsection{Conclusion}

The findings support other studies indicating that day care services can offer respite care and that day care services give both the relatives and the person with dementia a meaningful day. It is important for relatives to become accustomed to their new life situations and discover the meaning of caring through the relationship with their loved ones with the help of day care services. This new life can be described as traveling a route from a situation characterized by chaos and suffering to a new life situation with meaning through day care services. By allowing the persons with dementia to participate in activities that are facilitated and personalized and thus engaging, day care services seem to lead to a form of relief for the relatives. Even if they do find meaning, relatives must still face the agonies of making a choice about how to care for their loved ones with dementia in the future. The struggle to make a decision about the future of their loved ones and the dilemma of going to an institution versus aging in place will likely remain an ethical demand for some time to come and may even intensify in the future.

\subsection{Methodological Considerations}

This study focused on how relatives of persons with dementia who lived at home experienced their everyday lives when their loved ones were receiving day care ser- vices. Qualitative research allows flexibility and insight into complex phenomena and is therefore a strength in this kind of study. On the other hand, the qualitative method does not seek objectivity but instead seeks people's genuine experiences and must, therefore, act subjectively. The main limitation of this study is its small number of informants. The study includes only eight relatives as informants, but they do represent different genders, a wide range of relations, and a wide range in the distances that they lived from their loved ones. This diversity may contribute to the strength of this study. Another limitation may be that the relatives received day care services from two types of day care service, which may affect the loved ones' participation in activities in one way or the other; however, they were all participating in day care services involving green care. In one of the interviews, both the daughter and the wife who has dementia participated in the interview, with the husband acting as the primary informant. This could have both a positive and a negative effect on the interview outcome. On one hand, the husband could withhold information to avoid hurting his wife. On the other hand, the presence of the daughter and the wife contributed to a richer interview, because they both provided useful input during the interview. It is also important to note that this is only one of several possible interpretations.

\section{ACKNOWLEDGEMENTS}

The authors would like to thanks participants who made this study possible.

\section{REFERENCES}

[1] Alzheimer's Association (2012) Alzheimer's disease facts and figures. Alzheimer's \& Dementia, 8, 131-168. doi:10.1016/j.jalz.2012.02.001

[2] O’Connell B, Hawkins, M., Ostaszkiewicz, J. and Millar, L. (2012) Careers' perspectives of respite care in Australia: An evaluative study. Contemporary Nurse: A Journal for the Australian Nursing Profession, 41, 111-119.

[3] Glemsk (2007) Men ikke glemt! Om dagens situasjon og framtidas utfordringer for å styrke tjenestetilbudet til personer med demens. Sosialog helsedirektoratet. Avdeling omsorg og tannhelse, Oslo.

[4] Demensplan 2015 (2007) Helseogomsorgs departement et, Oslo.

[5] Zank, S. and Schacke, C. (2002) Evaluation of geriatric day care units: Effects on patients and caregivers. Journals of Gerontology Series B: Psychological Sciences \& Social Sciences, 57B, 348. doi:10.1093/geronb/57.4.P348

[6] Chumbler, N.R., Grimm, J.W., Cody, M. and Beck, C. (2003) Gender, kinship and caregiver burden: The case of community-dwelling memory impaired seniors. International Journal of Geriatric Psychiatry, 18, 722-732. doi:10.1002/gps.912 
[7] Andrén, S. and Elmståhl, S. (2008) The relationship between caregiver burden, caregivers' perceived health and their sense of coherence in caring for elders with dementia. Journal of Clinical Nursing, 17, 790-799. doi:10.1111/j.1365-2702.2007.02066.x

[8] Watts, J.H. and Teitelman, J. (2005) Achieving a restorative mental break for family caregivers of persons with Alzheimer's disease. Australian Occupational Therapy Journal, 52, 282-292.

doi:10.1111/j.1440-1630.2005.00524.x

[9] Kim, H., Chang, M., Rose, K. and Kim, S. (2012) Predictors of caregiver burden in caregivers of individuals with dementia. Journal of Advanced Nursing, 68, 846855. doi:10.1111/j.1365-2648.2011.05787.x

[10] Beaudreau, S.A., Spira, A.P., Gray, H.L., Depp, C.A., Long, J., Rothkopf, M. and Gallagher-Thompson, D. (2008) The Relationship between objectively measured sleep disturbance and dementia family caregiver distress and burden. Journal of Geriatric Psychiatry \& Neurology, 21, 159-165. doi:10.1177/0891988708316857

[11] Brodaty, H., Green, A. and Koschera, A. (2003) Metaanalysis of psychosocial interventions for caregivers of people with dementia. Journal of the American Geriatrics Society, 51, 657-664. doi:10.1034/j.1600-0579.2003.00210.x

[12] Van Den Wijngaart, M.A.G., Vernooij-Dassen, M.J.F.J. and Felling, A.J.A. (2007) The influence of stressors, appraisal and personal conditions on the burden of spousal caregivers of persons with dementia. Aging \& Mental Health, 11, 626-636. doi:10.1080/13607860701368463

[13] Miranda-Castillo, C., Woods, B. and Orrell, M. (2013) The needs of people with dementia living at home from user, caregiver and professional perspectives: A crosssectional survey. BMC Health Services Research, 13, 43. doi:10.1186/1472-6963-13-43

[14] De Bruin, S.R., Oosting, S.J., Tobi, H., Blauw, Y.H., Schols, J.M. and De Groot, C.P. (2010) Day care at green care farms: A novel way to stimulate dietary intake of community-dwelling older people with dementia? Journal of Nutrition Health \& Aging, 14, 352-357. doi:10.1007/s12603-010-0079-9

[15] Gústafsdóttir, M. (2011) Beneficial care approaches in specialized daycare units for persons with dementia. American Journal of Alzheimer's Disease \& Other Dementias, 26, 240-246. doi:10.1177/1533317511402315

[16] Bruin, S.R.D., Oosting, S.J., Kuin, Y., Hoefnagels, E.C.M., Blauw, Y.H., Groot, L.C.P.G.M.D. and Schols, J.M.G.A. (2009) Green care farms promote activity among elderly people with dementia. Journal of Housing for the Elderly, 23, 368-389. doi:10.1080/02763890903327275

[17] Kvale, S. (2007) Doing interviews. SAGE, Los Angeles.

[18] Patton, M.Q. (2002) Qualitative research \& evaluation methods.

[19] Granskär, M. and Höglund-Nielsen, B. (2012) Tillämpad kvalitativ forskning inom hälsooch sjukvård. Studentlitteratur, Lund.

[20] Graneheim, U.H. and Lundman, B. (2004) Qualitative content analysis in nursing research: Concepts, proce- dures and measures to achieve trustworthiness. Nurse Education Today, 24, 105-112.

doi:10.1016/j.nedt.2003.10.001

[21] Sandelowski, M. (1994) We are the stories we tell: Narrative knowing in nursing practice. Journal of Holistic Nursing, 12, 23-33. doi:10.1177/089801019401200105

[22] Oliver, P. (2010) The student's guide to research ethics. Open University Press, Maidenhead.

[23] Golden, M.A., Whaley, B.B. and Stone, A.M. (2012) "The system is beginning to shut down": Utilizing caregivers' metaphors for dementia, persons with dementia, and caregiving. Applied Nursing Research, 25, 146-151. doi:10.1016/j.apnr.2011.02.001

[24] Doka, K.J. (2010) Grief, multiple loss and dementia. Bereavement Care, 29, 15-20. doi:10.1080/02682621.2010.522374

[25] Betts Adams, K., McClendon, M.J. and Smyth, K.A. (2008) Personal losses and relationship quality in dementia caregiving. Dementia, 7, 301-319. doi:10.1177/1471301208093286

[26] Etters, L., Goodall, D. and Harrison, B.E. (2008) Caregiver burden among dementia patient caregivers: A review of the literature. Journal of the American Academy of Nurse Practitioners, 20, 423-428. doi:10.1111/j.1745-7599.2008.00342.x

[27] Willyard, J., Miller, K., Shoemaker, M. and Addison, P. (2008) Making sense of sibling responsibility for family caregiving. Qualitative Health Research, 18, 1673-1686. doi:10.1177/1049732308327195

[28] Quinn, C., Clare, L. and Woods, R.T. (2010) The impact of motivations and meanings on the wellbeing of caregivers of people with dementia: A systematic review. International Psychogeriatrics, 22, 43-55. doi:10.1017/S1041610209990810

[29] Moyle, W., Kellett, U., Ballantyne, A. and Gracia, N. (2011) Dementia and loneliness: An Australian perspective. Journal of Clinical Nursing, 20, 1445-1453. doi:10.1111/j.1365-2702.2010.03549.x

[30] Gústafsdóttir, M. (2011) Beneficial care approaches in specialized daycare units for persons with dementia. American Journal of Alzheimer's Disease and Other Dementias, 26, 240-246. doi:10.1177/1533317511402315

[31] de la Cuesta-Benjumea, C. (2011) Strategies for the relief of burden in advanced dementia care-giving. Journal of Advanced Nursing, 67, 1790-1799. doi:10.1111/j.1365-2648.2010.05607.x

[32] Lund, D.A., Utz, R., Caserta, M.S. and Wright, S.D. (2009) Examining what caregivers do during respite time to make respite more effective. Journal of Applied Gerontology, 28, 109-131. doi:10.1177/0733464808323448

[33] Menne, H.L., Johnson, J.D., Whitlatch, C.J. and Schwartz, S.M. (2012) Activity preferences of persons with dementia. Activities, Adaptation \& Aging, 36, 195-213. doi:10.1080/01924788.2012.696234

[34] Ducharme, F., Couture, M. and Lamontagne, J. (2012) Decision-making process of family caregivers regarding placement of a cognitively impaired elderly relative. Home Health Care Services Quarterly, 31, 197-218. 


$$
\text { doi:10.1080/01621424.2012.681572 }
$$

[35] Bern-Klug, M. (2008) The emotional context facing nursing home residents' families: A call for role reinforcement strategies from nursing homes and the community. Journal of the American Medical Directors Association, 9, 3644. doi:10.1016/j.jamda.2007.08.010

[36] Davies, S. and Nolan, M. (2004) "Making the move": Relatives' experiences of the transition to a care home. Health \& Social Care in the Community, 12, 517-526. doi:10.1111/j.1365-2524.2004.00535.x

[37] Butcher, H.K., Holkup, P.A., Park, M. and Maas, M. (2001) Thematic analysis of the experience of making a decision to place a family member with Alzheimer's disease in a special care unit. Research in Nursing \& Health, 24, 470-480. doi:10.1002/nur.10005

[38] Elliott, B.A., Gessert, C.E. and Peden-McAlpine, C. (2009) Family decision-making in advanced dementia: Narrative and ethics. Scandinavian Journal of Caring Sciences, 23, 251-258. doi:10.1111/j.1471-6712.2008.00613.X

[39] Eriksson, K., Olsson, K.A. Peterson, C.I. and Zetterlund,
J.E. (2006) The suffering human being. Nordic Studies Press, Chicago.

[40] Andrén, S. and Elmståhl, S. (2005) Family caregivers' subjective experiences of satisfaction in dementia care: Aspects of burden, subjective health and sense of coherence. Scandinavian Journal of Caring Sciences, 19, 157168. doi:10.1111/j.1471-6712.2005.00328.x

[41] Shim, B. Barroso, J. and Davis, L.L. (2012) A comparative qualitative analysis of stories of spousal caregivers of people with dementia: Negative, ambivalent, and positive experiences. International Journal of Nursing Studies, 49, 220-229. doi:10.1016/j.ijnurstu.2011.09.003

[42] Frankl, V.E. (1969) The will to meaning: Foundations and applications of logotheraphy. World Publishing Company, New York.

[43] Løgstrup, K.E. (1997) The ethical demand. University of Notre Dame Press, Notre Dame.

http://www.fhi.no/eway/default.aspx?pid=239\&trg=List 6212\&Main_6157=6263:0:25,5980\&MainContent_6263 =6464:0:25,5981\&List_6212=6218:0:25,5987:1:0:0:::0:0 